\title{
Teorias de género y cine. Un aporte a los estudios de la representación ${ }^{1}$
}

\author{
Paula Iadevito ${ }^{2}$
}

\author{
Universidad de Buenos Aires, Buenos Aires, Argentina ${ }^{3}$ \\ paulaiadevito@yahoo.com.ar
}

Recibido: 23 de septiembre de 2013

Aceptado: 29 de enero de 2014

\begin{abstract}
Artículo de revisión que realiza un estado de la cuestión de los movimientos analíticos que vinculan pensamiento feminista y teoria filmica. El abordaje destaca la productividad y la pertinencia de analizar las narrativas del cine desde una perspectiva de género. Se incluyen algunas reflexiones en torno a una investigación sobre la identidad femenina en Corea a través de las representaciones y las narrativas de las experiencias de las mujeres en el cine surcoreano. Dicha investigación se desarrolló gracias a una beca doctoral de la Universidad de Buenos Aires [2006 - 2008], y de una beca tipo II para la escritura de la tesis otorgada por el Consejo Nacional de Investigaciones Científicas y Técnicas CONICET, Argentina [2008 - 2011].

2 Doctora de la Universidad de Buenos Aires en Ciencias Sociales. Licenciada en Sociología y Profesora de Enseñanza Secundaria Normal y Especial en Sociología de la misma universidad. Investigadora asistente del CONICET Argentina.

3 Investigadora del Instituto de Investigaciones Gino Germani de la Facultad de Ciencias Sociales de la Universidad de Buenos Aires, con participación en las áreas de la Sociología de la Cultura y los Estudios del Este Asiático.
\end{abstract}

Documento accesible en línea desde la siguiente dirección: http://revistas.javeriana.edu.co 


\title{
Teorias de género y cine. Un aporte a los estudios de la representación \\ Resumen
}

El artículo indaga la relación entre género y cine como aporte a los estudios de la representación en el campo de la investigación social. En primer término, se exponen las características básicas de la cultura visual en la sociedad global atendiendo a los modos de pensar la identidad y el género en este contexto general y actual. En segundo término, se revisan los vínculos históricos entre feminismos y cine, y entre estudios de género y cine enfatizando en la perspectiva teórica de Teresa De Lauretis. En tercer término, se postula el uso del filme en el proceso de investigación social a partir de una experiencia que -sobre la base de construir una mirada analitica en el eje cine/ género/ sociedad- persiguió el objetivo de identificar, conocer e interpretar los cambios en la identidad femenina en Corea desde los sentidos y significados que condensa el espacio cinematográfico. Este trabajo concluye destacando la productividad y la relevancia de entrecruzar los estudios de género y los estudios sobre cine en el actual campo problemático de las Ciencias Sociales, profundamente signado por una diversidad de objetos/ sujetos de estudio y de 'nuevos' enfoques epistemológicos, teóricos y metodológicos.

Palabras clave: cine; género; sociedad; investigación social

\section{Theories of gender and cinema. A contribution to the representation studies}

\begin{abstract}
The article explores the relationship between gender and cinema as a contribution to the study of representation in the field of social research. First, the basic features of visual culture in the global society are presented keeping in mind the identity and gender mindsets in this general and current context. Second, the historical links between feminisms and cinema are reviewed as well as between studies of gender and cinema, emphasizing on the theoretical perspective of Teresa De Lauretis. Third, it is postulated the use of film in the process of social research from an experience that based on building an analytical look at the axis cinema / gender / society-pursued the objective of identifying, understanding and explaining the changes in the female identity in Korea from the senses and meanings that cinematic space condenses. This paper concludes highlighting the relevance and productivity of interweaving gender and film studies in the current problematic field of Social Sciences, deeply marked by a diversity of objects / subjects of study and 'new' epistemological, theoretical and methodological approaches.
\end{abstract}

Keywords: cinema; gender; society; social research

\section{Teorias de gênero e cinema. Uma contribuição para os estudos da representação \\ Resumo}

O artigo investiga a relação entre gênero e cinema como uma contribuição para os estudos da representação no campo da pesquisa social. Em primeiro lugar, expõem-se as características básicas da cultura visual na sociedade global atendendo os modos de pensar a identidade e o gênero nesse contexto geral e atual. Em segundo lugar, são revistos os vínculos históricos entre feminismos e cinema, e entre estudos de gênero e cinema enfatizando na perspectiva teórica de Teresa de Lauretis. Em terceiro lugar, postula-se o uso do filme no processo de pesquisa social a partir de uma experiência que -sobre a base de construir um olhar analítico no eixo cine/ gênero/ sociedade- perseguiu o objetivo de identificar, conhecer e interpretar as mudanças na identidade feminina em Coréia desde os sentidos e significados que o espaço cinematográfico condensa. Este trabalho conclui destacando a produtividade e a relevância de entrecruzar os estudos de gênero e os estudos sobre cinema no atual campo problemático das Ciências Sociais, profundamente marcado por uma diversidade de objetos/ sujeitos de estudo e de 'novos' enfoques epistemológicos, teóricos e metodológicos.

Palavras-chave: cinema; gênero; sociedade; pesquisa social 


\section{Introducción}

El mundo social actual se halla signado por la impregnación de 'lo visual', de los signos y las imágenes circulantes e imperantes en el campo cultural, que configuran el escenario visual y virtual de la contemporaneidad. De modo tal que en la sociedad global, la palabra acompañada de la imagen se ha convertido en un tipo de relato que no solo genera placer visual sino que constituye un dispositivo con la capacidad de interpelar(nos) en el plano de 'lo social' y 'lo subjetivo'.

En este marco, en la comunidad académica de las Ciencias Sociales se observa actualmente una tendencia a considerar el cine más como medio configurador de un discurso acerca de la realidad social -subsumiendo las cuestiones de imagen y sonido- que como objeto de estudio en sí mismo. Las contribuciones de Ana Amado y Nora Domínguez (2004), Gonzalo Aguilar (2006) y Susana Sel (2007), entre otros, se enmarcan dentro de esta nueva perspectiva de análisis en el campo de la investigación social. El hecho de concebir al cine como medio y/o dispositivo supone forjarlo como un terreno óptimo para el rastreo de las representaciones culturales de los sujetos, las identidades y las subjetividades generizadas.

A través del filme -en tanto narración- se habilita el acceso a los diferentes ámbitos de lo social: vidas cotidianas, vidas heroicas, conflictos familiares, conflictos políticos, deseos, sentimientos, mitos, leyendas, etcétera. De este modo, dichos abordajes se distancian de aquellos que, considerando al cine como objeto, buscan comprender el lenguaje fílmico y sus lógicas internas, es decir, se centran en el análisis de los códigos técnicos de representación visual y/o auditiva (Aumont, 1989; Aumont y Marie 1988; entre otros). Por su parte, los estudios de género han ido incorporando paulatinamente el análisis cultural de las imágenes y las visualidades para abordar las representaciones y los estereotipos de 'lo femenino' y 'lo masculino'.

Los aportes de las teorias del discurso, la teoría crítica y los estudios culturales han sido fundamentales para comprender la conformación de las identidades y el género en tanto representaciones concebidas en su dimensión significante, es decir, en su materialidad: como signos. En este sentido, desde una concepción de las identidades y el género como categorías teóricas interpeladas y construidas desde una simbología cultural atravesada por relaciones de poder y disputas por el sentido social, consideramos relevante reflexionar en torno a los vínculos entre teorias de género y cine. 
Los objetivos propuestos para este trabajo son, por un lado revisar las vinculaciones históricas entre feminismos / teorias de género y cine y por otro lado, reflexionar en torno a la pertinencia y la potencialidad de las visualidades para acceder a los procesos de significación del mundo y las relaciones sociales en el contexto de la sociedad global y tecnológica.

Los supuestos que guían el presente abordaje son: a) el cine constituye una fuente primaria de indagación acertada en el campo de la investigación social para leer analiticamente e interpretar los procesos identitarios y de subjetivación generizada; b) la perspectiva de género en el análisis filmico resulta productiva para comprender la relación entre mujeres y hombres a través de la historia e identificar los mecanismos de reproducción y cuestionamiento de las representaciones culturales y simbólicas hegemónicas; c) las narrativas del cine configuran espacios de significación que abren dimensiones ideológicas desde las cuales es posible observar las modalidades en que las marcas identitarias y de género instituyen las redes culturales de una sociedad.

Algunos interrogantes formulados en esta dirección son: ¿cuál ha sido la relación histórica entre feminismos y teoría filmica?, ¿qué cambios introdujo la apertura de miradas propagadas por los estudios culturales en la intercepción de dichos campos del saber?, ¿qué lugar ocupan las visualidades en el mundo social actual? y ¿de qué manera interviene 'lo visual' en la construcción de las identidades y el género?

El texto se organiza de acuerdo al siguiente recorrido descriptivo analítico. En la primera parte se abordan aspectos generales de la sociedad global signada por las imágenes y las visualidades. Desde este marco general, se alude a ciertas interpretaciones y conceptualizaciones sobre las nociones de identidad, género y representación cinematográfica. En la segunda parte se reconstruyen los debates al interior del campo de saber que articula feminismos y teoría filmica caracterizando los principales movimientos analíticos en su contexto de emergencia y producción, y atendiendo a las críticas que cada uno ha suscitado. En la tercera parte se hace énfasis en la relación entre estudios de género y cine, incluyendo algunos aportes centrales de la perspectiva teórica de Teresa de Lauretis que invitan a (re)pensar la subjetividad desde la dimensión discursiva y simbólica y su carácter generizado.

Por último, luego de la revisión conceptual recapitulamos ciertas premisas de una investigación que analizó las representaciones de las 'mujeres coreanas' en la ficción fílmica. Sobre la base de concebir una relación dinámica entre cine y sociedad, dicha investigación incorporó 
al género como perspectiva de análisis, un modo de mirar, una lente que permitió visualizar no solo qué tipo de sociedad y de sujeto (femenino), histórico y ficcional estaba siendo representado, sino también interpretado y construido en y por el espacio cinematográfico.

\section{Globalización y cultura visual}

En las últimas décadas, la configuración de las sociedades capitalistas fue redefinida en términos de un nuevo orden global de la economía que dio lugar a una apertura mundial del mercado. Este proceso denominado como globalización de la economía y de la tecnología produjo importantes cambios socioculturales (Bauman, 1999). Una consecuencia de este proceso es la configuración de un espacio social donde predomina la concentración de signos e imágenes. Así, la denominada cultura visual impregna e irrumpe eficazmente en los distintos ámbitos de la vida humana (Lash y Urry, 1998).

Dicho de otro modo, las visualidades pasan a adquirir -en el seno de la sociedad tecnológica- una presencia predominante en la vida cotidiana de los sujetos y cada vez más relevancia cultural como forma de comprensión, conocimiento y dominio político del mundo (Arfuch y Devalle, 2009). En concreto, se ha ido consolidando la idea de que 'lo visual' se relaciona con determinados aspectos históricos y culturales que determinan 'modos de ver' que, a su vez, hacen referencia a elementos simbólicos y materiales tendientes a las operaciones ideológicas (Penhos, 2005).

Los medios de comunicación -en su diversidad de formas- constituyen un poderoso instrumento de plasmación y control de los imaginarios sociales. Imágenes y narrativas visuales se han convertido en dispositivos claves en la construcción de la sociedad, los sujetos, las identidades y las subjetividades generizadas. Pues decimos entonces que el fenómeno histórico de la globalización ha contribuido a una redefinición de las identidades de pertenencia de los sujetos y que en este proceso, las visualidades han desempeñado un rol fundamental y fundacional de las nuevas formas culturales que conforman la denominada cultura visual.

Sin embargo, Colaizzi (2007) nos advierte acerca de la necesidad de fomentar la conciencia de la naturaleza construida, ni inocente ni neutral, de las imágenes que configuran las representaciones culturales y estéticas del mundo que nos rodea. En un mismo sentido, se 
afirma que los sentidos y significados que las imágenes producen no son estables ni corresponden siempre a lo perceptible de ellas. Siguiendo las premisas de la Teoría Post-estructuralista, las interpretaciones que sugieren son disimiles de acuerdo al contexto en el cual son leídas y, por esta razón, son concebibles como "co-creadoras, ya que diferentes grupos interpretan las imágenes según sus propias tradiciones culturales y necesidades contemporáneas" (Duncum, 2004).

Desde esta perspectiva teórica, recuperamos también ciertas premisas de la teoría del discurso para entender al cine como industria cultural y aparato cinematográfico que adscribe a determinado contexto histórico pero, fundamentalmente, para interpretarlo como fuerza creadora de imágenes, identidades e identificaciones que cuentan con la capacidad de interpelación ideológica en términos althusserianos. En palabras de Arfuch,

[...] de lo que la imagen trae, en su materialidad, en el modo de su referencia, hay algo que sólo se dirime en la mirada, en el diálogo, contingente y azaroso, con su eventual perceptor [...]. En esa interacción, en esa apropiación [...] se juega verdaderamente su sentido $(2009, \mathrm{~s} / \mathrm{p})$.

Retomando el planteamiento teórico de Berger (2000), señalamos que los 'modos de ver' se encuentran sujetos a un orden social que, sustentado a través del tiempo, configuran un hábito a partir del cual se crean condiciones de diálogo con los 'otros' atravesados por la diversidad y la contradicción.

\section{Identidad, género y representación cinematográfica}

En los debates teóricos que se fueron produciendo hacia fines del siglo $\mathrm{XX}$, la filosofia y el feminismo lograron converger en varios sentidos. La filosofia, por un lado, se encontraba en plena puesta en cuestión de la tradición ilustrada de pensamiento, a la vez que el feminismo, por otro lado, discutía el conjunto de oposiciones binarias -propio de la concepción ilustrada de la identidad- que había determinado los modos de pensar y de definir la realidad y los sujetos, pero también al lenguaje. Desde ambos espacios de producción de conocimiento, se pretendió dejar de concebir al lenguaje como un mediador entre las cosas y los sujetos, o como un mero 'nomenclador', para comenzar a considerarlo parte inherente de los sujetos, las identidades y el género. 
Concebir la identidad como una relación social implica asumir que se encuentra atravesada por el poder y, en consecuencia, también por las jerarquías, las disputas por el sentido y las ideologias. Quizás sea Hall (1996) quien haya planteado uno de los interrogantes más provocadores desde la perspectiva deconstructiva de los estudios culturales: “¿Quien necesita identidad?”. La identidad de la que nos habla Stuart Hall no refiere ya a aquel concepto ligado a cualidades tales como lo esencial, lo innato, lo determinado, lo permanente, la mismidad. Por el contrario, el autor nos dice: "este concepto de identidad no señala ese núcleo estable del yo que, de principio a fin, se desenvuelve sin cambios a través de todas las vicisitudes de la historia [...]" (Hall, 1996, p. 17).

Así entendida la identidad es diversa y posicional y se construye en relación con la historia y la tradición en constantes procesos de (re) significación. Por ello, las identidades -tanto personales como culturales- nunca son unificadas y menos aún en los tiempos que corren, en los que existen "nunca singulares sino múltiplemente construidas a través de diferentes discursos, prácticas, y posiciones a menudo intersectadas y antagónicas" (Hall, 1996, p. 3). Construidas en la diferencia y no fuera de ella, las identidades dan cuenta de que solo ante la presencia perturbadora de un 'otro' se torna posible la constitución de sí mismo.

Desde esta perspectiva teórica, la identidad es 'como un efecto'; es el resultado de su narrativización a través de formaciones discursivas que -mediante ciertas reglas de formación y modalidades de enunciación- construyen posiciones de sujeto en tensión y conflicto, resistencia y negociación permanentes (Ricoeur, 1991) . Por la capacidad que las identidades tienen de trascender su dimensión material, o mejor dicho, de traspasar los limites prácticos de su existencia para situarse en el plano de lo discursivo simbólico, quedan atravesadas por una multiplicidad de relatos y discursos (siendo el discurso cinematográfico uno de ellos) que las proveen de elementos emocionales e ideológicos de identificación.

Siguiendo la conceptualización hecha por Paul Ricoeur postulamos entonces a la ficción filmica como narrativa, entendida esta como acto discursivo de puesta en sentido y como lugar privilegiado de construcción de la temporalidad y la experiencia donde se fundan

No pretendemos dar cuenta de todas las definiciones y problematizaciones acerca de la identidad, ni de las teorias y debates en los que esta noción - de un modo u otro- se ha visto involucrada, sino marcar nuestra perspectiva de análisis. 
posiciones de sujeto y subjetividades. En este sentido, las experiencias de las mujeres representadas y narradas por el cine son 'algo' que, como diría Hall (2000), no puede ser pensado como 'un pasado', una cristalización o sentido objetivado, sino que están siempre siendo construidas por una memoria, una fantasía, una narrativa, un mito que expresa una cierta visión cultural del mundo.

En cuanto al género -establecido como una tecnología- lo caracterizamos como un proceso complejo propio de la modernidad orientado a producir sujetos 'normales' a partir de la regulación de la praxis que -desde el plano simbólico y material- pregona la heterosexualidad como matriz normativa. Concebido de este modo, el género no responde a rasgos del orden de 'lo natural e inmutable' sino que se trata de una categoría interpelada y construida desde la simbología cultural y desde los dispositivos y relaciones de poder que la atraviesan. Por consiguiente, lo afirmamos como una experiencia del sujeto que acontece en el orden de la representación, entendiendo dicha noción por su capacidad de mediación entre la realidad y lo simbólico (De Lauretis, 1987; Lamas, 1995; Scott, 1990).

Según Berger (2000), los 'modos de ver' se encuentran sujetos a un orden social que, sustentado a través del tiempo, configuran un hábito. En lo que atañe a las representaciones cinematográficas el 'modo de ver' históricamente configurado resulta ser a la vez, aquel que entra en juego como horizonte cultural. Otra de las afirmaciones del autor sostiene que las expresiones del arte responden a un punto de vista masculino, es decir, reponen una visión cultural masculina hegemónica. Frente a ello, las enunciaciones visuales y verbales del arte fueron fuente de reflexión pormenorizada y continua por parte del pensamiento feminista.

A continuación nos abocamos a la relación entre feminismos y teoría filmica, la cual reviste complejidades y controversias a raíz de la variación histórica de ambos campos de saber ${ }^{5}$.

Una versión preliminar de la revisión teórica sobre feminismo y cine que aquí desarrollamos fue llevada a cabo por Iadevito y Zambrini (2010). 


\section{Feminismos y teoria filmica ${ }^{6}$}

El pensamiento feminista contemporáneo, entre sus preocupaciones fundamentales, ha indagado en torno al eje cine/ género/ sociedad, con el objetivo de cuestionar el carácter dominante de los discursos y narrativas cinematográficas. Si bien dentro del feminismo pueden identificarse distintas posturas con respecto al cine, existe consenso en cuanto al hecho de concebir a la cinematografia como una actividad semiótica. Basadas en la línea teórica de Metz (1979) -quien propone una lectura sobre el cine valiéndose de los aportes de la semiótica y del psicoanálisis-, las feministas conciben al cine como productor de significados. Dicho lineamiento resulta concordante y por ende funcional, con la premisa fundante del feminismo que postula que el carácter político es inherente a toda experiencia subjetiva.

Las primeras teorias feministas sobre cine se desarrollaron en Estados Unidos y en Gran Bretaña reflexionando y analizando -principalmente- sobre el cine hecho por mujeres. Como antecedentes podemos mencionar el primer Festival Internacional de Cine de Mujeres de Nueva York (1972) y el Festival de Mujeres y Cine de Toronto (1973), los cuales coinciden con la publicación de tres libros de critica feminista: From reverence to rape, de Molly Haskell (1975); Popcorn Venus (1973), de Marjorie Rosen; Women and their sexuality in the New Film (1974), de Joan Mellen. En estos años también se lanzó la revista estadounidense Women and Film.

Estos textos 'pioneros' buscaron examinar el lugar de la mujer en el cine clásico presuponiendo la existencia de un vínculo entre mundo real y representación cinematográfica. En la misma época en Gran Bretaña, dos sucesos propiciaron un primer acercamiento a la teoria feminista del cine: la proyección de 'cine de mujeres' en el Festival de Cine de Edimburgo (1972) y la publicación de Notes on Women's Cinema (1973), editado por Claire Johnston. La corriente británica se apoyó en las disciplinas, teorías y métodos que -por entonces- estaban siendo utilizados por la teoría filmica en general ${ }^{7}$.

Dichas producciones feministas artísticas y teóricas relacionadas con el cine, a ambos lados del Atlántico, surgieron asociadas a la expansión de movimientos de vanguardia tales como el impresionismo

\footnotetext{
No es el propósito de este artículo realizar un exhaustivo repaso de nombres y trabajos sobre feminismo y cine. Se busca señalar algunos estudios relevantes que han ofrecido enfoques novedosos y han propiciado la apertura de líneas de investigación.

Para ampliar los antecedentes al respeto se sugiere el trabajo de Kuhn (1991).
} 
francés, el expresionismo alemán, el surrealismo, el dadaísmo y el formalismo ruso ${ }^{8}$. En cuanto al espacio cinematográfico éste logró ampliar el horizonte representacional y cultural al punto de proclamarse como 'cine diferente', centrándose en temáticas del universo femenino y optando por una mirada femenina para abordarlas y mostrarlas. Es decir, fue convirtiéndose en una alternativa a los modos dominantes de la representación cinematográfica, de ahí, el interés de la crítica feminista por indagarlo y estudiarlo como nuevo fenómeno.

De esta manera, se han ido sentando las bases para el desarrollo de dos posturas teóricas claves que -progresivamente- fueron configurando el campo de estudios que hace converger feminismo y cine.

Por un lado, se encuentran las teorias feministas que -valorizando la dimensión significante de la obra artística- han desarrollado estudios sobre feminismo y cine que ponen el énfasis en el espacio cinematográfico como productor de sentidos y significados. Desde esta postura, 'lo femenino' es entendido como dimensión subordinada y bloqueada por el orden patriarcal y el espacio cinematográfico como dispositivo de denuncia y manifestación de reivindicaciones feministas y femeninas ${ }^{9}$. Por otro lado, están las teorias feministas que han planteado la necesidad de cuestionar los procesos mismos de producción de significados sobre la base de considerarlos ideológicos per se. Esta línea de pensamiento complejiza la aproximación feminista al quehacer cinematográfico desde el momento en que sostiene que los modos de representación/narración constituyen una subjetividad (tanto femenina como masculina) que corresponde a una cultura patriarcal. Además, se considera que el modo femenino de representar/ narrar es el adecuado para cuestionar y trastocar la constitución ideológica de las formas dominantes de la representación ${ }^{10}$.

Mientras que la primera postura pone el acento en el resultado concreto de la cinematografia (el significado), la segunda postura establece que lo sustantivo se vincula al proceso mismo de producción cinematográfica (el significante).

Paulatinamente, el cine hecho por mujeres comenzó a proyectarse hacia direcciones diferentes: el cine experimental y el cine documental político y social.

9 Referencias ampliadas bajo el subtítulo La década del setenta, del presente apartado.

${ }^{10}$ Referencias ampliadas bajo el subtitulo Las nuevas miradas del presente apartado, y en el siguiente: Teoría de género y cine. 


\section{La década del setenta}

En este contexto, las teorías feministas sobre cine se plantearon como objetivo la negación del realismo ilusionista y comenzaron a interesarse en las imágenes del cine clásico como un objeto casi perfecto para analizar los modos de funcionamiento de la ideología en la construcción de la diferencia sexual (Amado, 2000).

Las nuevas tendencias de la década de 1970 responden a voces feministas provenientes de ámbitos culturales e ideológicos diferentes: la de origen norteamericano -que manifiesta un marcado interés sociológico y fenomenológico- y la británica, que se encuentra organizada a partir de un enfoque teórico y analítico. La primera propició con mayor fuerza la inclusión de áreas de opresión femenina que hasta el momento no habian sido representadas ni narradas, mientras que la segunda se dedicó a promover la participación crítica y comprometida por parte de la audiencia, incentivando el abandono del rol de espectador pasivo para adoptar un rol de sujeto-receptor-activo ${ }^{11}$.

Entre todos los abordajes de la época, se destacan los trabajos de Cook y Johnston (1990/1974), que justifican la idea de un cine deconstructivo y la propuesta teórica de Mulvey (1990/1975), que desarrolla las controvertidas nociones de anti-cine/ contra-cine ${ }^{12}$. Como vemos, el pensamiento predominante en el campo feminista de la época se organizó en torno a la idea de ruptura del flujo de la narrativa, basándose en la necesidad de interrogar y descifrar los procesos de producción fílmica.

Pero probablemente la propuesta de Mulvey es la que revista en este contexto, una mayor productividad a la hora de evaluar los alcances del pensamiento crítico feminista con relación al cine ${ }^{13}$. Las ideas desarrolladas por la autora fueron las que dispararon dentro de esta corriente de pensamiento crítico el debate con respecto a la eficacia de los aportes del psicoanálisis en el ejercicio de interpretación de las formaciones culturales. Este tópico de discusión se vuelve especialmente

${ }^{11}$ Se puede identificar también otra tendencia que reconoce en el cine hecho por mujeres, estilos y acentos que pretenden una ruptura con los procedimientos del cine clásico. Al analizar el impacto que este tipo de cine genera en la audiencia, esta tendencia ha planteado estrategias innovadoras, tanto cinematográficas como feministas.

12 Dichas nociones atañen tanto a la forma cinematográfica como a la relación con el público, en un intento por de-construir la dicotomía naturalizante de los binomios de identificación pasivo/ femenino y activo/ masculino.

${ }^{13}$ A saber, el feminismo de los años setenta puede sintetizarse en las siguientes ideas pilares: a) la desestructuración del contenido exige un replanteamiento de la forma; b) la elaboración y aplicación de un canon femenino es el que permite medir el contenido contracultural de toda obra. 
interesante porque pone de relieve la cuestión de las diferencias en oposición a la diferencia -en singular- construida por el discurso del feminismo crítico.

No obstante, existe una serie de planteamientos teóricos que se distancian de las premisas hasta ahora expuestas y que cobran relevancia en la medida en que complejizan los entrecruzamientos entre feminismo y cine. Mencionamos algunas: Bergstrom (1979) cuestiona la visión de la diferencia sexual como polaridad rígida; Doane (1990/1982) afirma que el proceso narrativo de la mujer en los sistemas de representación es una narración del y para el varón (el cine narra a la mujer, pero no la deja narrarse) ${ }^{14}$; las postulaciones de Gaines (1990/1984) que asevera que el contra-cine bloquea -de algún modoel campo de investigación feminismo-cine por no habilitar un análisis de la interacción entre la cultura femenil y la cultura dominante; la argumentación de Rich (1990/1980), que asegura que la mirada femenina absorbe los patrones patriarcales y sexistas, re-significando y elaborando formas propias de resistencia; y por último, la advertencia de Kaplan (1983) sobre el descuido del pensamiento feminista que incorpora la teoría psicoanalítica, pero deja de lado las actualizaciones que exige el contexto actual (por ejemplo, las mutaciones en las configuraciones familiares contemporáneas poco tienen que ver con el modelo de familia victoriana en la que se basa la teoría de Freud).

Más allá de la diversidad de líneas -cada una con sus especificidades teóricas y metodológicas-, es importante destacar que durante este período todas las posturas contribuyeron a sentar las bases para el desarrollo de un nuevo pensamiento dentro del campo feminista con relación al cine y la representación visual. Con los años surgieron nuevos debates e intercambios nutridos por los aportes de la filosofia, la semiótica y el pensamiento post-estructuralista, que han re-configurado las especulaciones feministas en torno a la dinámica entre cine y formas de representación de las mujeres y de 'lo femenino' (Armstrong, 1991; De Lauretis, 1987; 2001; Kristeva, 1981).

\section{Las nuevas miradas}

Sobre la base de los antecedentes teóricos que acabamos de reseñar, en el transcurso de la década de 1980 surgen nuevas líneas de investigación abocadas a reflexionar sobre las formas de representación

${ }^{14}$ En respuesta a esto se vuelven significativas las teorias de la subjetividad femenil desarrolladas por autoras tales como Luce Irigaray, Sarah Kofman y Michele Montrelay, entre otras. 
femenina en y por el espacio cinematográfico. El núcleo de los desarrollos teóricos emergentes apunta a modificar el modo de abordaje de las imágenes (en especial, de las imágenes de las mujeres). Se busca, en este sentido, comprenderlas no solo a partir de las lógicas de sentido que instaura el patriarcado, sino como potenciales productoras de contradicciones tanto en el plano social como subjetivo (Sabsay, 2007).

Las teorias que articulan feminismo y cine se proponen superar la lógica binaria recreada en las representaciones/narraciones cinematográficas. Una exponente central de dicha corriente teórica es De Lauretis, que en sus estudios sobre feminismo, cine y semiótica plantea -como punto de partida- la necesidad de distinguir las nociones de mujer-ficcional y mujer(es)-sujetos históricos. Además, propone pensar la interrelación entre ambas nociones, los modelos epistemológicos, los presupuestos y las jerarquías implícitas en los discursos y representaciones de las mujeres. La autora considera al cine como una actividad relevante en la medida en que produce efectos de significado y percepción, auto-imágenes y posiciones subjetivas que involucran a todos los agentes del proceso cinematográfico.

Desde este enfoque, De Lauretis (1987) cuestiona la lectura realizada por el pensamiento feminista de mediados de la década del setenta. Su crítica fundamental señala que el feminismo, en su intento por cuestionar al patriarcado, ha recaido en el dogmatismo y la reproducción de la lógica binaria. Siguiendo su misma línea de pensamiento se ubican las reflexiones de Juhasz (1994), quien considera que la de-construcción de los binarismos del patriarcado -pregonada por el pensamiento feminista crítico- no hizo más que contribuir a la edificación de binarios feministas.

Así, constatamos que pensadoras como De Lauretis y Juhasz (cabe también mencionar a Chandra T. Mohanty, entre otras) han problematizado por un lado, las nociones fijas y monoliticas que conducen a la reproducción de la lógica binaria y por otro lado, han cuestionado las capacidades de representación ensayadas hasta el momento por la teoria feminista.

Las nuevas contribuciones han posibilitado la redefinición del rol del cine en el campo del pensamiento feminista y de los estudios de género, caracterizándolo de aquí en adelante más como una tecnología social que cuenta con el potencial de operar a través de una mirada y un lenguaje propio capaces de expresar las diferencias en plural, visibilizando la heterogeneidad y la contradictoria dinámica social. 


\section{Teorias de género y cine}

A partir de lo desarrollado hasta aqui, podemos decir que los cruces entre feminismo y teoría cinematográfica abrieron las sendas para el surgimiento no solo de nuevas postulaciones teóricas dentro del campo de pensamiento feminista, sino también de expresiones artísticas que incluyeron la perspectiva de género y el enfoque de las llamadas nuevas identidades sociales y/o minorias genéricas. Ejemplos de estas nuevas expresiones artísticas son las manifestaciones estéticas del Camp -tal como las define Amícola (1974)-, el denominado cine Queer $^{15}$ y el cine GLTTB, entre otros ${ }^{16}$.

Las teorias de género tienden a desnaturalizar las imágenes para recuperar el carácter social y culturalmente construido. Mientras los estudios de la década de 1970 enfatizaron el placer del voyeur masculino y la mujer fetichizada, en el principio de los noventas aparecen con insistencia textos que giran en torno a los estudios sobre el posmodernismo y el pos-colonialismo. Ahondar en las representaciones de la diversidad sexual, de género y raza son algunas de las líneas profundizadas en los últimos tiempos. En efecto, el abordaje del cine desde una perspectiva de género supone ampliar el horizonte histórico de la representación, siempre atravesada por los discursos sociales y modelos culturales que la configuran.

Desde el punto de vista sociológico, el arte y las vanguardias son indisociables del contexto histórico en el cual son producidos. El cine -desde su peculiar lenguaje artístico- refleja y produce sentido al mismo tiempo y este proceso se potencia y refuerza con la llegada de las imágenes a la circulación mediática y masiva. Es por ello que el cine es considerado a partir de su doble circulación: por un lado, en los espacios masivos y mediáticos; por otro, en los circuitos vanguardísticos. En este sentido, se asume que es mayor el consumo masivo de un filme si la temática narrada está naturalizada y visibilizada socialmente.

${ }^{15}$ El cine queer surge en paralelo a las nuevas conceptualizaciones de la teoría de género -como las presentes en la obra de Butler (2001)- interesadas en generar modos de construir el género más allá del esquema binario (masculino/femenino) y del mandato heterosexual. En consecuencia, se trata de un cine que se destacó por el carácter radical de sus producciones y por la forma de tratar las identidades sexuales, desafiando la norma heteronormativa y las imágenes positivas de la homosexualidad, promovidas por el movimiento GLTTB. Fue ganando terreno en los institutos de género estadounidense enfocándose en reflejar la diferencia sexual sin autocensuras (Weed y Schor, 1997).

${ }^{16}$ Estas corrientes artísticas se pronuncian a partir de las nuevas líneas de expresiones y rupturas, problematizando la cuestión de género mediante los cruces de la teoría y el arte. El trabajo de J. Halberstam (2008) sobre masculinidades femeninas, que propone un abordaje socio-semiótico de materiales filmicos, resulta ilustrativo al respecto. 
En cambio, se postula que lo transgresor y des-naturalizante suele estar en otras zonas de menor masividad (Morin, 1962).

A raíz de estas consideraciones, desde el campo de los estudios de género se piensa al arte y por ende al cine, como espacio privilegiado para la expresión e innovación de nuevas representaciones que no siempre son concordantes con lo normativo. Entendiendo la representación más allá del registro de 'lo real', el cine puede establecerse como un complejo de representaciones que habilita intervenciones en el ámbito político, puesto que produce significaciones, simbolismos y múltiples interpretaciones de sentido. En tanto expresión cultural y como productor de narrativas acerca de la vida social, el cine crea a la vez relatos sobre las experiencias de género, asumiendo que estas atraviesan un proceso de semiotización que las torna significativas y comunicables (Colaizzi, 2007). De este modo, el cine se transforma en locus propicio para pensar los discursos y las normativas sociales, la alteridad y la diversidad, que son a la vez, partes constitutivas de todo proceso identitario -individual y/o colectivo- del cual emana, como hemos visto, un carácter político.

\section{La perspectiva de Teresa De Lauretis}

A grandes rasgos, los aportes de De Lauretis, se refieren a la idea de una subjetividad generizada construida en un proceso permanente basado en la experiencia del sujeto. La autora la define de la siguiente manera:

[...] es una construcción sin final, no un punto de partida o de llegada fijo desde donde uno interactúa con el mundo. Contrariamente, es el efecto de esta interacción lo que llamo experiencia, y si así se produce, no mediante ideas y valores externos, causas materiales, sino con el compromiso personal, subjetivo en las actividades, discursos e instituciones que dotan de importancia (valor, significado y afecto) a los acontecimientos del mundo (1992, pp. 54-55).

En esta trayectoria, cada persona adquiere su género, lo que implica que la subjetividad no está (sobre) determinada por la biología ni tampoco por una 'intencionalidad libre y racional', sino por la experiencia que ella define en la interacción semiótica (Alcoff, 2001, p. 90). Al concepto de subjetividad De Lauretis le reconoce un dinamismo inherente: el compromiso del sujeto con la realidad social se constituye 
en una interacción en constante movimiento, variación y apertura a las variaciones dadas por el auto-análisis producto de la práctica reflexiva (con otros sujetos). Además, el proceso histórico de conciencia que supone la construcción de la subjetividad conlleva formas de compromiso y lucha politica (Alcoff, 2001, p. 90).

Lo central aquí es que la teoría de De Lauretis nos conduce a pensar una subjetividad generizada en la cual intervienen tanto la dimensión discursiva como la de las prácticas concretas de los sujetos. Desde su perspectiva, el género queda definido como una representación que se ha ido construyendo históricamente a través de otras diversas representaciones, ideologias y discursos. En palabras de la autora:

[...] la construcción del género prosigue en nuestros días a través de las diversas tecnologías del género (como el cine) y diversos discursos institucionales (como la teoria) y tienen el poder de controlar el campo del significado social y por tanto de producir, promover e 'implantar' la representación del género. (1992, p. 54)

Según De Lauretis (1987), las experiencias de las mujeres -como las de todo ser social-, se construyen a partir de los efectos del lenguaje y la representación. En tal sentido, el cine no solo es un aparato material sino una actividad significante que implica y constituye al sujeto, pues instala a la mujer en un particular orden social y natural, la coloca en una cierta posición del significado y la fija en una cierta identificación. Se trata de un verdadero escenario de conformación de identidades que produce y reproduce estereotipos sociales, según tendencias hegemónicas y leyes tácitas que, por otra parte, contribuye a consolidar (Arfuch, 1996). Sin embargo, Arfuch nos advierte que esta actividad significante es esencialmente dinámica:

[...] no se cierra en sentidos cristalizados y aunque -rara vezasuma carácter vanguardista, en la cadena de reenvíos es posible encontrar una cosa y su contraria" (1996, p. 115).

Esto equivale a decir que no siempre encontramos el mismo modo de representar y narrar a las mujeres, sus experiencias y su universo de sentidos sino que, incluso es posible encontrar imágenes estereotipadas absolutamente opuestas. 
El siguiente apartado presenta algunas de las premisas fundamentales de una investigación sobre las representaciones de las 'mujeres coreanas' en el cine, más específicamente, sobre la construcción de una mirada teórica basada en una perspectiva de género para indagar los mecanismos de producción de las figuras femeninas y sus devenires en la ficción fílmica seleccionada.

\section{Apuntes de investigación}

La investigación sobre las representaciones de las 'mujeres coreanas' en el espacio cinematográfico, plasmada en la tesis doctoral Mujeres históricas, mujeres de ficción. Dilemas y tensiones entre tradición y modernidad en el cine surcoreano contemporáneo (2011), se origina en el interés sobre los cambios en la subjetividad femenina en Corea del Sur como producto del proceso de modernización occidental, el cual implicó una serie de transformaciones socioculturales con gran impacto en el estilo de vida coreano. La familia -en tanto principal unidad estructuradora de la sociedad- vio alterados los roles y funciones de sus integrantes y en este marco, las experiencias de las mujeres comenzaron a resignificarse en los nuevos escenarios (Byung-ho Chung, 2001; Doménech del Río, 2004; Fallis, 2004; Sei-wha Chung 1987; entre otros).

En relación al caso objeto de nuestro análisis, 'las experiencias de las mujeres y las presencias de lo femenino en el cine surcoreano contemporáneo', nos propusimos develar cómo, en relación con qué y con quiénes las mujeres son representadas y narradas por la ficción filmica. El corpus de análisis fue conformado por una selección de filmes del Nuevo Cine Coreano ${ }^{17}$, y la introducción de una obra del cine clásico ${ }^{18}$ con el propósito de contrastar modos de representar las experiencias de mujeres en contextos diferentes: la sociedad moderna actual y la sociedad tradicional confuciana, respectivamente ${ }^{19}$.

17 A Good Lawyer's Wife (La esposa del buen abogado) (2003), de Im Sang-soo; My Mother, The Mermaid (Mi madre, la sirena) (2004), de Park Heung-shik y Family Ties (Lazos Familiares) (2006), de Kim Tae-young.

18 Chunhyang (2000), en la adaptación del renombrado director coreano Im Kwon-taek.

19 La investigación realizó un exhaustivo relevamiento del cine coreano que atravesó distintas etapas de sistematización y lecturas preliminares dando lugar a la formulación de criterios de selección y ejes de indagación hasta lograr la conformación del corpus filmico definitivo para el análisis. Dicha tarea se realizó en un diálogo permanente con la teoría y el contexto histórico. 
La investigación adoptó el enfoque teórico que entiende al cine como espacio de subjetivación basado en la construcción discursiva/ narrativa de las identidades y el género. De acuerdo con este enfoque general, se trabajó el eje cine-(mujer)-sociedad desde una mirada que buscó descifrar las luchas por el sentido que se producen y son dirimidas en el espacio simbólico de la representación y que intervienen en la constitución de las experiencias que moldean las identidades individuales y colectivas. La construcción del 'ser-mujer' y del 'universo femenino' fue leída como producto de lo que el lenguaje dice, hace e instituye (Austin, 1990/1962; Bourdieu, 1987). Es decir, por lo que el cine muestra, re-crea y proyecta, y vuelve a mostrar luego de la reapropiación subjetiva. Porque el espacio cinematográfico no solo opera reflejando los procesos sociales sino que también los genera dando lugar a nuevos 'efectos de sentido' que terminan de configurarse a partir de la mirada del receptor-espectador. Dicho de otro modo, una vez proyectadas las imágenes filmicas estamos en condiciones de hablar de una relación dinámica entre cine y sociedad (Sorlín, 1985). Dinámica que, en nuestro caso, fue indagada desde una perspectiva de género que no solo diferenció 'lo femenino' de 'lo masculino', sino que enfatizó la mutua implicancia entre ambas condiciones de existencia y del devenir de la experiencia del sujeto.

En este punto, acordamos con aquellas corrientes del pensamiento feminista reciente que plantean la necesidad de incorporar al género como herramienta analítica para la comprensión de las relaciones sociales y como categoría que interviene en la constitución del entramado social y la subjetividad, y las interrelaciones entre ambas esferas. Por ello, el modelo analítico al que recurrimos buscó visibilizar las formas concretas, variadas y múltiples de la experiencia, la actividad y la representación tanto de mujeres como de hombres, considerando que unas y otras son inseparables y que la cuestión de género (o de los sexos, considerando al sexo sin caer en determinismos biológicos) alude a relaciones y procesos sociales más que a un fenómeno o a un conjunto de ellos.

Se incorporó la conceptualización de Scott (1990), que define al género como 'la organización social de las relaciones entre los sexos' habilitando la reflexión en torno al carácter polivalente de esta categoría conformada por los múltiples segmentos heterogéneos experienciales que complejizan el esquema identitario 'femenino'/ 'masculino', y que nos permite plantearla como herramienta específica y fundamental para el análisis social; no obstante, su mirada resultó insuficiente para dar cuenta de los complejos procesos de significación 
del espacio cinemático. En este sentido, la postura de Marta Lamas (1995) al definir la construcción del género como la simbolización de la diferencia sexual y plantear que se constituye culturalmente en un conjunto de prácticas, ideas y discursos, resultó adecuada para pensar las representaciones de género en el cine. Pero a la luz de los recientes desarrollos de la teoría feminista, no podemos desconocer que las construcciones simbólicas de las identidades y el género se producen en medio -y como producto- de un sistema de tensiones y relaciones de poder. Priorizamos en nuestro enfoque la perspectiva de De Lauretis (1987) que postula al género como una tecnología en la que confluyen necesidades, experiencias, derechos y obligaciones tanto de mujeres como de varones, según los roles asignados y las expectativas sociales naturalizadas ${ }^{20}$.

Por otra parte, una marcada perspectiva histórica nos permitió reconstruir las experiencias de las mujeres de la sociedad coreana de todas las épocas: pre-tradicional, tradicional, moderna, democrática y actual. La dimensión histórica nos brindó la posibilidad de leer e interpretar las representaciones del sujeto femenino considerando elementos y características de los escenarios en cada contexto histórico. En efecto, prevaleció una mirada sociológica, histórica y de análisis cultural que incorporó la reflexión de género como una de las articulaciones del marco teórico multidisciplinario construido para el abordaje de las mujeres de ficción.

Como correlato metodológico, la investigación recurrió a un enfoque cualitativo sustentado en el análisis narrativo del filme. Siendo el objetivo principal descifrar las significaciones y los sentidos del discurso cultural cinematográfico, el análisis narrativo resultó la estrategia metodológica más acertada. Dicha estrategia cuenta con la capacidad de evaluar la estructura filmica mediante el estudio de aspectos vitales de una narración: personajes, acciones y acontecimientos ${ }^{21}$. La narración filmica ficcional es entendida entonces, como una composición

${ }^{20}$ Butler (2001) señala la imposibilidad de desligar el género de las intersecciones culturales y políticas en que invariablemente se produce y se mantiene. La autora alza su crítica contra la idea de patriarcado universal y el binarismo masculino/femenino, pues considera que operan descontextualizando la especificidad de lo femenino y desligando a las mujeres de la clase, la etnia y demás ejes de relaciones de poder que constituyen la identidad. Ciertos aportes de la teoria butleriana fueron incorporados en tanto guiños conceptuales que enriquecen la perspectiva analítica; sin embargo, la complejidad de su pensamiento excedió los alcances de la investigación doctoral cuyo objetivo no era analizar las identidades de género sino desplegar una mirada de género sobre las narrativas de cine seleccionadas.

${ }^{21}$ La estrategia metodológica de análisis narrativo deja de lado el análisis de los códigos técnicos de representación visual y auditiva, y la semiótica de las imágenes en movimiento (planos, escenas, secuencias, montaje), ya que estos modos de encarar el objeto implican el trabajo con otras epistemologías y métodos. 
estructural que relata y describe un suceso en orden cronológico o mediante un conflicto y el análisis narrativo en tanto estrategia que busca aproximarse al tema, al argumento y al asunto tratado en el filme. (Barthes, 1982; Geertz, 1994; White, 1992).

Al adoptar una perspectiva de análisis no determinista y dinámica entre cine y sociedad, el diálogo entre ficción y realidad reconoce que el filme -en tanto 'pequeño' relato- no solo aprehende 'lo social' sino que también lo construye discursivamente. Esta doble intervención convierte al cine en un dispositivo generador de 'efectos de realidad', con participación en la construcción de sentidos y significados que se plasman en el imaginario social y moldean las subjetividades generizadas (De Lauretis, 2001).

Nuestro análisis filmico giró en torno a los modos de representar y narrar al sujeto femenino en relación con los mundos sociales y familiares que se han ido configurando como parte del cambio cultural producto del proceso de modernización, por medio de la desagregación de los siguientes ejes de indagación: 1. Escenarios familiares y roles de género en transformación; 2. Actitudes (femeninas) frente al matrimonio; 3. Trayectorias educativas y laborales de las mujeres; 4. Sexualidad femenina; 5. Violencias de género; 6. Maternidad; 7. Amor materno y relaciones de parentesco; 8. Relaciones amorosas y (re)definiciones del amor; 9. Resistencias (femeninas) a la dominación masculina. El análisis filmico por ejes temáticos fue recuperando la teoría y el contexto histórico para avanzar en la interpretación y la reflexión crítica en torno a las experiencias de las 'mujeres coreanas'.

Se priorizó una perspectiva de análisis dinámica y dialógica de las transformaciones ocurridas en todos los niveles de la sociedad coreana que nos evitara caer en una caracterización de modelos puros: modelo tradicional y moderno de sociedad, familia y mujer. Siendo esta una de nuestras premisas principales, la lectura filmica hizo hincapié en los dilemas y las tensiones inherentes a las narrativas de ficción con el fin de identificar 'posiciones intermedias' del sujeto femenino que se configuran a partir de experiencias que se dirimen en el diálogo -más o menos conflictivo- entre tradición y modernidad. Constatamos al respecto la imposibilidad de hablar de modelos sociales 'puros' al igual que de representaciones culturales con sentidos y significados clausurados y univocos. Por ello, señalamos que las mujeres históricas/ mujeres de ficción no expresan imágenes cerradas, positivas o negativas del sermujer, sino un devenir contingente atravesado por relaciones de poder y en diálogo con las otredades culturales y de género. 
Como venimos argumentando, el cine -en tanto lenguaje que expresa realidades sociales pero también experiencias del sujeto- se constituye en un indicador más de la identidad como 'algo' en permanente transformación. Nuestras mujeres de ficción expresan el estado de evolución en que se encuentra la identidad femenina en Corea: ni tradicional ni moderna, configurándose en el seno de una realidad social signada por el cambio cultural en pleno progreso. La concepción teórica que subyace aquí entiende que la identidad del 'yo' se produce en la 'puesta en sentido' de la narración y en relación con 'otros', es decir, en un proceso de creación y recreación contingente y constante (Arfuch, 2002a; 2002b; Hall, 1996).

Problematizar los sistemas de representación y narración de las experiencias de las 'mujeres' en el cine contemporáneo constituyó un aporte al proceso de construcción simbólica de la identidad femenina en Corea, que opera configurando la trama cultural y de género de la sociedad peninsular actual. Sin embargo, la aproximación a la ficción filmica surcoreana significó mucho más que un encuentro con ciertas representaciones de las mujeres pertenecientes a esta cultura otra que me permitieron construir sentidos y significados en torno a los modos en que fueron construidas. Producto de este encuentro, además he podido llevar a cabo un ejercicio de autocrítica y de confrontación con la extendida y consensuada visión sobre 'lo asiático-coreano' como 'algo' exótico y extraño, tanto por la distancia geográfica como cultural.

En particular, este estudio significó un aporte a la comprensión de las relaciones de género que -al ser desnaturalizadas- encuentran numerosos puntos en común con el esquema de relaciones de género del contexto social local (occidental, latinoamericano, argentino). El hecho de haber ensayado una lectura de los textos filmicos desde lo que Colaizzi (2007) denomina 'mirada bizca' nos permitió develar situaciones y características sociales, culturales y de género que -en apariencia- pueden considerarse como a-históricas, homogéneas y universales.

\section{Palabras finales}

En la etapa actual de la modernidad tardía, las visualidades juegan un rol activo dentro de la configuración de las complejas tramas culturales con marcas de género, estableciendo anclajes identitarios con respecto a qué es un hombre y qué es una mujer. Lo mismo sucede con las expectativas sociales en torno a los comportamientos que 
suponen 'lo femenino' y 'lo masculino' según los modelos culturales hegemónicos. En relación a ello, destacamos la necesidad de ejercitar una mirada sociológica que de-construya la visualidad como un proceso atravesado por formas culturales y relaciones de poder, y que imprimen de determinado carácter ideológico a los actos de mirar e interpretar la vida social y por ende, las identidades y el género.

Las principales corrientes del pensamiento feminista que han proliferado -desde la década del setenta en adelante- plantearon la necesidad de revelar los prejuicios culturales e ideológicos que tenían como base los conflictos entre los sexos y las diferencias de género. Dichas corrientes han ido posibilitando el surgimiento de nuevas tradiciones de pensamiento, una nueva historia feminista del arte y una renovada manifestación del arte feminista, cuyos principios radicaron en mostrar el modo en que tanto el campo académico como el campo artístico crearon históricamente discursos aparentemente objetivos, neutrales y universalmente estéticos.

Estos son discursos emergentes en un contexto ideológico de dominación masculina en el que el lugar de las mujeres ha sido el de reforzar los estereotipos que las asociaban, en primer término, con la sexualidad a modo de objeto y en segundo término, como agentes pasivos del ámbito doméstico y familiar, entre otras posibles figuraciones signadas por la desigualdad sexual y/o de género. Lo que el pensamiento feminista señaló fue que estos discursos remitían a complejos sub-textos en torno a las sexualidades y la cuestión de género y las ideologías que las envolvían (Bloch, 2003). En este marco, los estudios de género vinieron a señalar enfáticamente que las nociones de identidad y de género son construcciones culturales e ideológico-simbólicas y que, en el marco de la sociedad actual, se expresan con fuerza a nivel de la iconicidad y en el campo de la representación.

Recapitulando, afirmamos que en tanto recurso adoptado en los procesos de investigación social, el cine ha sido incorporado primeramente como objeto de estudio en sí mismo y más recientemente, como fuente de análisis. En el primer caso se han producido investigaciones centradas en la complejidad del fenómeno cinematográfico -entendido como medio de comunicación- y que toman en cuenta sus condiciones de producción, masificación, universalización, difusión y recepción, entre otras. En el segundo caso, el tipo de abordaje promocionó estudios que se enfocaron en las potencialidades del cine como un lenguaje y expresión artístico-cultural que permite acceder a la sociedad mediante las ideas que capta, produce y proyecta a través de su materia. 
Consideramos que el debate dentro de las ciencias sociales con respecto a la inclusión del cine en el proceso científico, radica en las diferencias epistemológicas en torno al arte y la teoría. Desde el paradigma cientificista, el arte es vislumbrado como un espacio dotado de flexibilidad y alejado de definiciones dogmáticas; en cambio, la ciencia positiva requiere de la definición de un objeto y para ello, se basa en sistemas clasificatorios. Desde esta perspectiva, el arte se piensa como el significante y la teoría científico-social como el significado. Postulamos entonces que el uso del cine resulta un recurso apropiado para reducir el exceso de la abstracción teórica. Un filme sustentado en la teoría puede resultar un vehículo adecuado y fructífero para la generación del conocimiento, ya que el lenguaje artístico tiene el potencial de poner en acto (imagen-movimiento) lo abstracto. En otras palabras la teoría abstracta, mediante el cine, puede adquirir corporeidad.

En definitiva, en la investigación sobre las representaciones de las experiencias de las mujeres en el cine surcoreano, nuestro ejercicio de indagación de los filmes desde un enfoque metodológico cualitativo de análisis cultural y narrativo -en un acto de lectura que priorizó la mirada de género- problematiza las imágenes y las figuraciones de 'lo femenino' (y de lo masculino en diálogo) representadas y narradas en el campo de la ficción filmica. De este modo, parafraseando a De Lauretis (1992), podemos decir que el cine constituyó -en tanto tecnología de género- una fuente de primer orden para la exploración de las experiencias y las relaciones (entre mujeres y hombres) que convergen en una configuración contemporánea de la identidad femenina en Corea.

\section{Referencias}

Aguilar, G. (2006). Otros mundos. Un ensayo sobre nuevo cine argentino. Buenos Aires: Santiago Arcos Editor.

Alcoff, L. (2001). Feminismo cultural versus post-estructuralismo: la crisis de la identidad en la teoria feminista. En M. Navarro, y C. Stimpson (Comps.). Nuevas Direcciones (pp. 65-106). Buenos Aires: Fondo de Cultura Económica.

Althusser, L. (1970). Ideología y aparatos ideológicos del Estado (notas para una investigación). En L. Althusser. Posiciones (pp. 69-12). Barcelona: Anagrama.

Amado, A. (2000). La teoría del cine y el marco de la historia. Entrevista a Laura Mulvey. Entrepasados. IX, (18/19), 173-181. 
Amado, A. y Domínguez, N. (Comps.) (2004). Lazos de Familia. Herencias, cuerpos, ficciones. Buenos Aires: Paidós.

Amícola, J. (1974). Camp y posvanguardia. Manifestaciones culturales de un siglo fenecido. Buenos Aires: Paidós.

Arfuch, L. (1996). Una mujer es una mujer. Notas para una semiótica de lo femenino en los medios. Mora, 2, 112-124.

Arfuch, L. (2002a). El espacio biográfico. Dilemas de la subjetividad contemporánea. Buenos Aires: Fondo de Cultura Económica.

Arfuch, L. (2002b). Identidades, Sujetos y Subjetividades. Buenos Aires: Prometeo.

Arfuch, L. (2009). Dilemas de la imagen: modos de ver y de ser. Rayando los confines. Revista virtual de pensamiento crítico. Disponible en: http://www. rayandolosconfines.com.ar/reflex83_arfuch.html.

Arfuch, L. y Devalle, V. (2009). Visualidades sin fin. Imagen y diseño en la sociedad global. Buenos Aires: Prometeo.

Armstrong, N. (1991). Deseo y ficción doméstica. Madrid: Ediciones Cátedra.

Aumont, J. (1989). Estética del cine. Espacio filmico, montaje, narración, lenguaje. Barcelona: Paidós.

Aumont, J. y Marie, M. (1988). Análisis del film. Buenos Aires: Paidós.

Austin, J. (1990/1962). Cómo hacer cosas con palabras. Palabras y acciones. Barcelona: Paidós.

Bauman, Z. (1999). La globalización. Consecuencias humanas. Brasil: Fondo de Cultura Económica.

Barthes, R. (1982). Análisis estructural de los relatos. Barcelona: Editorial Buenos Aires.

Berger, J. (2000). Modos de ver. Barcelona: Editorial Gustavo Gili.

Bergstrom, J. (1979). Enunciation and sexual difference. Cámara Obscura, 3-4, 32-69.

Bloch, A. (2003). Y... toca ahora el turno para la mirada de mujer: análisis de género y creación en las artes visuales contemporáneas. Estudios sobre las culturas contemporáneas, II-IX (17), 91-113.

Bo-gyeong, S. y Chul, S. (Productor) \& Sang-soo, I. (Director). (2003). A Good Lawyer's Wife. [Cinta cinematográfica]. Corea del Sur.

Bourdieu, P. (1987). Cosas Dichas. Barcelona: Gedisa.

Butler, J. (2001). El género en disputa. El feminismo y la subversión de identidad. México DF: Universidad Nacional Autónoma de México, Paidós.

Colaizzi, G. (1995). Feminismo y teoría filmica. Valencia: Epísteme. 
Colaizzi, G. (2006). Género y representación. Postestructuralismo y crisis de la modernidad. Madrid: Biblioteca Nueva.

Colaizzi, G. (2007). La pasión del significante. Madrid: Biblioteca Nueva.

Cook, P. y Johnston, C. (1990/1974). The place of women in the cinema of Raoul Walsh. En P. Erens (Ed.). Issues in Feminist Film Criticism (pp. 19-27). Bloomington: Indiana University Press.

Chung, B.(2001). Changes in Korea family structure and the conflicts of ideology and practice in early socialization. Korea Journal 41 (4), 123-143.

Chung, S.(1987). (Ed.). Challenges for Women: Women's Studies in Korea (pp.). Seoul: Ewha Womans University Press.

De Lauretis, T. (1987). Technologies of Gender. Essays on Theory, Film and Fiction. Bloomington: Indiana University Press.

De Lauretis, T. (1992). Alicia ya no. Feminismo, semiótica, cine. Madrid: Cátedra.

De Lauretis, T. (2000). La tecnología del género. En T. De Lauretis. Diferencias (pp. 33-69). Madrid: Horas y Horas.

De Lauretis, T. (2001). Repensando el cine de mujeres: teoría estética y teoría feminista. En M. Navarro y C. Stimpson (Comps.). Nuevas Direcciones (pp. 203-232). Buenos Aires: Fondo de Cultura Económica.

Doane, M. A.(1990/1982). Film and the Masquerade. Theorizing the female spectator. En P. Erens (Ed.). Issues in Feminist Film Criticism (pp. 35-46). Bloomington: Indiana University Press.

Dok-woo, N. y Gyeong-hwan, L. (Productor) \& Heung-shik, P. y Hyeong-sok, H. (Director). (2004). My Mother, The Mermaid. [Cinta cinematográfica]. Corea del Sur.

Doménech del Río, A. J. (2004). Mujer, género y familia en Corea. Capítulo dentro de los materiales de la asignatura Género y Familia en Asia Oriental. UOC P03/87025/02412.

Duncum, P. (2004). Visual Culture isn't just visual: Multiliteracy, multimodality and meaning. Studies in Art Education, 45, 252-264.

Fallis, S. (2004). Women in Korean Society. The Korea Time (pp. 3). Seoul: The Korea Times Co. Ltd.

Gaines, J. (1990/1984). Women and representation. Can we enjoy alternative pleasuare? En P. Erens (Ed.). Issues in Feminist Film Criticism (pp. 75-92). Bloomington: Indiana University Press.

Geertz, C. (1994). Conocimiento local. Ensayos sobre la interpretación de las culturas. Barcelona: Gedisa.

Halberstam, J. (2008). Masculinidad Femenina. Barcelona: Egales.

Hall, S. (1996). Introduction: who needs identity? En S. Hall y P. Du Gay (Eds.). Questions of cultural identity (pp. 3-17). London: Sage Publications. 
Hall, S. (2000). Cultural Identity and Cinematic Representation. En R. Stam y T. Miller. Film and Theory (pp. 704-14). Oxford: Blackwell Publishers.

Haskell, M. (1975). From Reverence to Rape: The Treatment of Women in the Movies. London: New English Library Ltd.

Iadevito, P. y Zambrini, L. (2010). Feminismo, cine y sociedad: ensayo sobre la conformación de un campo problemático. Trabajo inédito, no publicado.

Johnston, C. (1973). Notes on Women's Cinema. London: Society for Education in Film and Television.

Juhasz, A. (1994). Nuestros auto-cuerpos, nosotras mismas. La representación de mujeres reales en el video feminista. Afterimage, 7, 10-14.

Kaplan, A. (1983). Women \& Film. Both sides of Camera. Nueva York: Routledge.

Kristeva, J. (1981). Semiótica 1 y 2. Madrid: Fundamentos.

Kuhn, A. (1991). Cine de mujeres. Feminismo y cine. Madrid: Cátedra.

Lamas, M. (1995). Usos, dificultades y posibilidades de la categoría género. La Ventana - Revista de estudios de género, 1, 9-61.

Lash, S. y Urry, J. (1998). Economías de signos y espacios. Sobre el capitalismo de la posorganización. Buenos Aires: Ed. Amorrortu.

Mellen, J. (1974). Women and their sexuality in the New Film. United Kingdom: Horizon Press.

Metz, C. (1979). Psicoanálisis y Cine. El significante imaginario. Barcelona: Gustavo Gilli.

Morin, E. (1962). El espiritu del tiempo. Madrid: Taurus.

Mulvey, L. (1990/1975). Visual pleasure and narrative cinema. En P. Erens (Ed.). Issues in Feminist Film Criticism (pp. 28-40). Bloomington: Indiana University Press.

Penhos, M. (2005). Ver, conocer, dominar. Imágenes de Sudamérica a fines del Siglo XVIII. Buenos Aires: Siglo Veintiuno Editores.

Rich, R. B. (1990/1980). In the name of feminist film criticism. En P. Erens (Ed.). Issues in Feminist Film Criticism (pp. 268-287). Bloomington: Indiana University Press.

Ricoeur, P. (1991). El sí y la identidad narrativa. En P. Ricoeur. Sí mismo como otro (pp. 138-172). México: Siglo Veintiuno Editores.

Rosen, M. (1973). Popcorn Venus. United Kingdom: Avon Books.

Sabsay, L. (2007). Los dilemas del antiesencialismo en la teoría feminista contemporánea: una reflexión en torno a Judith Butler. Almeria: El Ejido.

Sel, S. (2007). Cine y fotografía como intervención politica. Buenos Aires: Prometeo. 
Scott, J. (1990). El género: una categoría útil para el análisis histórico. En J. Amelang y M. Nash (Comp.). Historia y género: las mujeres en la Europa moderna y contemporánea (pp. 23-56). Valencia: Alfons el Magnanim.

Sorlín, P. (1985). Sociología del Cine. La apertura para la historia de mañana. México: Fondo de Cultura Económica.

Tae-woon, J. y Yong-kook, B. (Productor) \& Tae-yong, K. (Director). (2006). Family Ties. [Cinta cinematográfica]. Corea del Sur.

Tae-won, L. (Productor) \& Kwon-taek, I. (Director). (2000). Chunhyang. [Cinta cinematográfica]. Corea del Sur.

Weed, E. y Schor, N. (Eds.) (1997). Feminism meets queer theory. Bloomington: Indiana University Press.

White, H. (1992). El contenido de la forma. Narrativa, discurso y representación histórica. Barcelona: Paidós.

\section{Cómo citar este artículo}

Iadevito, P. (2014). Teorías de género y cine. Un aporte a los estudios de la representación. Universitas Humanística, 78, 211-237. http://dx.doi. org/10.11144/Javeriana.UH78.tgcu 